\title{
Protocolo de uso suplementar de tiamina em pacientes utilizando nutrição parenteral total no Hospital Universitário Walter Cantídio (HUWC)
}

\section{Protocol for the supplementary use of thiamine in patients undergoing total parenteral nutrition at Walter Cantídio University Hospital (HUWC)}

Luciana Rodrigues Façanha Barreto Medeiros ${ }^{1}$. Beatriz Amorim Beltrão ${ }^{2}$. Ana Cecília Santos Martins Cláudio Mourão ${ }^{3}$. Natália Linhares Ponte Aragão ${ }^{4}$. Alberto Hil Furtado Júnior ${ }^{4}$. Arnaldo Aires Peixoto Júnior ${ }^{5}$.

1 Intensivista, Unidade de Terapia Intensiva do Hospital Geral Dr. Waldemar Alcântara (HGWA). Residente de Terapia Intensiva, área de atuação em Nutrição enteral e parenteral, Hospital Universitário Walter Cantídio (HUWC), Universidade Federal do Ceará (UFC), Fortaleza, Ceará, Brasil. 2 Mestre em Enfermagem pela Universidade Federal do Ceará (UFC), Enfermeira da Unidade de Terapia Intensiva do Hospital Universitário Walter Cantídio (HUWC), Fortaleza, Ceará, Brasil. 3 Especialista em Nutrição enteral e parenteral pela Universidade Federal do Ceará (UFC). Intensivista da Unidade de Terapia Intensiva do Hospital Universitário Walter Cantídio (HUWC), Fortaleza, Ceará, Brasil. 4 Médico Intensivista, Unidade de Terapia Intensiva do Hospital Universitário Walter Cantídio (HUWC), Universidade Federal do Ceará (UFC), Fortaleza, Ceará, Brasil. 5 Doutor em Farmacologia pela Universidade Federal do Ceará (UFC). Supervisor do Programa de Residência Médica em Medicina Intensiva, Hospital Universitário Walter Cantídio (HUWC), Professor do Departamento de Medicina Clínica da Universidade Federal do Ceará (UFC), Fortaleza, Ceará, Brasil.

\section{RESUMO}

Objetivo: o presente trabalho visa propor um protocolo para suplementação de tiamina em pacientes utilizando nutrição parenteral no Hospital Universitário Walter Cantídio. Método: uma revisão de literatura foi utilizada para identificar fatores de risco e sinais e sintomas da deficiência de tiamina, bem como recomendações para suplementação desta. Foram também consultadas diretrizes clínicas utilizadas por grandes centros de saúde para detecção de déficit de tiamina e propostas de condutas para sua suplementação. Resultados: com base nas evidências levantadas, elaborou-se fluxograma contemplando recomendações para uso suplementar de tiamina em pacientes utilizando nutrição parenteral. Conclusão: o protocolo elaborado pode auxiliar a equipe assistencial quanto ao reconhecimento e tratamento da deficiência de tiamina em pacientes sob terapia nutricional parenteral.

Palavras-chave: Nutrição parenteral. Tiamina. Acidose láctica. Protocolos.

\section{ABSTRACT}

Objective: this study aims to propose a protocol for supplementary use of thiamine in patients undergoing total parenteral nutrition at the Hospital Universitário Walter Cantídio. Methods: a review of literature was performed to determine risk factors, signs and symptoms of thiamine deficiency and recommendations for its supplementation as well. Guidelines used by other healthcare units to detect thiamine deficit and its supplementation were also consulted. Results: based on actual evidences, a management protocol was made with recommendations to supplement thiamine in patients receiving total parenteral nutrition. Conclusion: this protocol can aid the assistance team to prompt recognize and treat thiamine deficiency in patients with parenteral nutrition.

Keywords: Parenteral Nutrition. Thiamine. Acidosis, lactic. Protocols.

Autor correspondente: Luciana Rodrigues Façanha Barreto Medeiros, Rua Capitão Francisco Pedro, 1290, Rodolfo Teófilo, Fortaleza, Ceará. CEP: 60430-370.Telefone: +55 85999629999 . E-mail: lucianarfb@gmail.com

Conflito de interesses: Não há qualquer conflito de interesses por parte de qualquer um dos autores.

Recebido em: 19 Set 2017; Revisado em: 27 Set 2017; Aceito em: 07 Nov 2017. 


\section{INTRODUÇÃO}

É comum que pacientes internados apresentem estado de má nutrição já na admissão hospitalar, seja por deterioração prévia associada a ingesta precária ou determinada pela própria doença. Tal condição pode levar a quadros clínicos com maior resposta inflamatória sistêmica, maior risco de infecções e complicações cirúrgicas, tais como fístulas e deiscências, gerando assim aumento da morbimortalidade, do tempo de permanência hospitalar e de desfechos desfavoráveis. ${ }^{1}$

A nutrição parenteral total (NPT) é utilizada como estratégia de exceção para terapia nutricional, sempre quando o trato gastrointestinal não está íntegro, sendo necessária em situações nas quais a terapia nutricional enteral não é possível ou está contraindicada. Através dela, é possível manter o aporte calórico e proteico, bem como veicular eletrólitos, durante estados de estresse catabólico. Dessa forma é garantida a oferta de nutrientes e eletrólitos, conforme as necessidades diárias do indivíduo. ${ }^{2}$

Entretanto, esta não é uma terapia isenta de riscos e complicações. $\mathrm{O}$ aporte de nutrientes e de eletrólitos garantido pela nutrição parenteral, associado a disfunções orgânicas frequentes nos pacientes, favorecem o surgimento de complicações metabólicas. Dentre elas, destacam-se aquelas ocasionadas pela deficiência de tiamina (vitamina B1), condição pouco reconhecida e habitualmente não tratada antes do surgimento de complicações. As principais complicações estão relacionadas ao surgimento de acidose láctica, com dano secundário em todos os tecidos, podendo também estar associado acometimento direto do sistema nervoso central e coração. ${ }^{3,4}$

Diante da relevância destas condições e do consequente impacto que têm para os pacientes em uso de nutrição parenteral, o presente trabalho visa descrever um protocolo de uso suplementar da tiamina em pacientes utilizando NPT em acompanhamento pelo Serviço de Nutrição Enteral e Parenteral do Hospital Universitário Walter Cantídio.

\section{MÉTODO}

Para elaboração deste protocolo, foi realizada a busca de artigos científicos das bases de dados MEDLINE (Literatura Internacional em Ciências da Saúde), SciELO (Scientific Electronic Library Online) e LILACS (Centro LatinoAmericano e do Caribe de Informação em Ciências da Saúde), em 15 de agosto de 2017. Os artigos foram selecionados a partir das seguintes palavras-chaves indexadas nos Descritores em Ciências da Saúde (DeCS): "Thiamine" (Tiamina), "Parenteral Nutrition" (Nutrição Parenteral), "Protocols" (Protocolos), sendo utilizado o recurso disponibilizado pelo operador booleano AND/OR, presentes no título, resumo ou entre as palavras chaves.

Após a busca conforme a estratégia descrita, foram selecionados artigos originais, relatos de casos, revisões de literatura, revisões sistemáticas, meta-análises e diretrizes que identificassem "fatores de risco para deficiência de tiamina", "manifestações clínicas associadas a deficiência de tiamina" e "condutas para suplementação desta vitamina em pacientes que necessitassem uso de nutrição parenteral".

Artigos originais nas línguas inglesa, portuguesa ou espanhola foram considerados na busca para elaboração do protocolo. Após avaliação crítica dos trabalhos selecionados e discussão das informações colhidas pelos médicos da Equipe Multiprofissional de Terapia Nutricional, foram extraídas as informações pertinentes e elaborado o protocolo com base nas melhores práticas recomendadas pela literatura.

\section{DISCUSSÃO}

A tiamina é uma vitamina hidrossolúvel que tem papel como coenzima nos processos do metabolismo de carboidratos, sendo fundamental para a descarboxilação do piruvato. As necessidades diárias de tiamina são garantidas através da ingesta alimentar e produção por componentes da flora intestinal. Ela é absorvida principalmente no jejuno e em menor grau no duodeno e íleo. ${ }^{5}$

Após sua absorção através de receptores específicos, a tiamina é convertida em pirofosfato de tiamina, sua forma ativa. Ela atua como coenzima da piruvato desidrogenase, responsável pela conversão de piruvato em acetil-coenzima $\mathrm{A}$ (AcetilCoA), o qual será oxidado através da reação do ácido tricarboxílico, conhecido como ciclo de Krebs, para geração de adenosina trifosfato (ATP). O pirofosfato de tiamina também atua como cofator da $\alpha$-cetoglutarato desidrogenase, também no ciclo de Krebs, e da transcetolase, na via das pentoses. ${ }^{6}$ A tiamina é ainda necessária para a conversão de ácido láctico em piruvato, que será metabolizado conforme descrito acima. Portanto, quando há carência dessa vitamina ocorre prejuízo tanto no metabolismo oxidativo de carboidratos, proteínas e ácidos graxos, bem como no metabolismo do ácido láctico, contribuindo para o aparecimento ou agravamento de hiperlactatemia e consequente acidose láctica. ${ }^{7}$

Sendo a tiamina uma vitamina essencial ao metabolismo energético, sua deficiência pode acarretar complicações, tais como a acidose lática, associada a dano tecidual, particularmente no sistema nervoso central, com manifestações variadas, e no sistema cardiovascular, com falência cardíaca em decorrência do elevado estresse metabólico. As complicações podem ser irreversíveis se a reposição de tiamina não ocorrer precocemente. ${ }^{8}$

Pacientes em terapia nutricional parenteral recebem soluções ricas em carboidratos para manter adequado balanço energético. Recomenda-se o uso de complexos multivitamínicos em associação a terapia nutricional parenteral total, ${ }^{9,10}$ porém, alguns complexos vitamínicos disponíveis atualmente são livres de tiamina, e o aumento abrupto da oxidação de carboidratos pode desencadear sua deficiência aguda por aceleração do consumo das reservas, especialmente nos gravemente enfermos. ${ }^{11}$ 
A deficiência de tiamina ocorre em situações de má nutrição, provocadas por baixa ingesta nutricional, por perdas de nutrientes ou por má absorção destes. Habitualmente, há mais de uma causa envolvida.

Com níveis insuficientes desta vitamina, o organismo aumenta o metabolismo anaeróbio, com redução do metabolismo do ácido láctico, levando a acidose metabólica refratária aos tratamentos convencionais e aumento da mortalidade em cerca de $50 \%{ }^{12,13}$

\section{Implicações clínicas}

Sabendo que é possível prevenir estas complicações, com redução de tempo de internação e morbimortalidade, todos os pacientes que possuem fator de risco para apresentar deficiência de tiamina devem ser identificados previamente a fim de prevenir piores desfechos. Os fatores de risco associados a deficiência de tiamina, identificados na literatura, estão listados no Quadro 1.

A deficiência de tiamina, no entanto, nem sempre cursa com manifestações clínicas óbvias, mas pode provocar sinais e sintomas relacionados a disfunção metabólica, neurológica e cardiovascular, especialmente em pacientes gravemente enfermos. Conforme identificado na literatura, o espectro dessas manifestações clínicas é variado. Estas manifestações clínicas estão listadas no Quadro 2.

Quadro 1. Fatores de risco associados a deficiência de tiamina.

\begin{tabular}{|l|l|}
\hline \multicolumn{2}{|l|}{ Fatores de risco } \\
\hline Alcoolismo & $\begin{array}{l}\text { Insuficiência cardíaca } \\
\text { congestiva }\end{array}$ \\
Jejum prolongado (acima de & Insuficiência renal \\
7 dias) & Sepse \\
Desnutrição grave & Trauma \\
Cirurgias bariátricas & Queimaduras \\
Hiperêmese gravídica & \\
\hline
\end{tabular}

Quadro 2. Manifestações clínicas associadas a deficiência de tiamina.

\begin{tabular}{|l|l|}
\hline \multicolumn{2}{|l|}{ Manifestações clínicas } \\
\hline Fraqueza muscular & Neuropatia periférica \\
Vômitos & Ataxia \\
Náuseas & Convulsões \\
Constipação & Acidose láctica \\
Edema & Síndrome de Wernicke-Korsakoff* \\
Falência cardíaca de & Beribéri** \\
alto débito & \\
\hline
\end{tabular}

Nota: *oftalmoplegia, nistagmo, psicose, ataxia e confusão mental; ** edema, parestesias, dor e fraqueza muscular.

Dentre as manifestações mais graves, destaca-se o acometimento do sistema nervoso central com consequente encefalopatia de Wernicke, caracterizada por nistagmo/ oftalmoplegia, ataxia e confusão mental. Mais comumente observada em pacientes com história de alcoolismo, essa condição deve ser suspeitada em indivíduos recebendo nutrição parenteral total, com qualquer fator de risco para deficiência de tiamina e que apresentem mudança aguda do estado mental ou marcha. $\mathrm{O}$ reconhecimento e tratamento precoces diminuem o risco de disfunção neurológica permanente e óbito. ${ }^{14}$

\section{Protocolo de uso suplementar de tiamina em pacientes utilizando nutrição parenteral total}

Deste modo, foi elaborado pela equipe multiprofissional de nutrição um fluxograma para orientar a suplementação de tiamina nos pacientes em uso de nutrição parenteral (Figura 1), conforme detalhado a seguir.

Figura 1. Fluxograma proposto para suplementação de tiamina em pacientes com NPT.

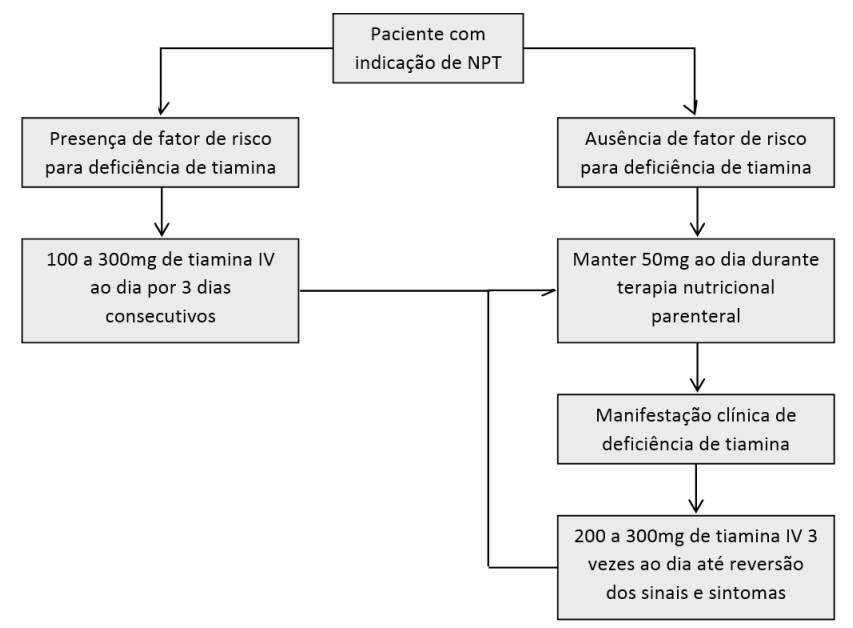

Nota: NPT (nutrição parenteral total), IV (via intravenosa).

- paciente grave, em uso de NPT, com fator de risco para deficiência de tiamina deverá receber 100-300mg de tiamina por via intravenosa (IV) ao dia nos primeiros 3 dias e manutenção de $50 \mathrm{mg} /$ dia IV durante a duração da terapia nutricional;

- em caso de manifestação clínica de deficiência de tiamina durante o uso de NPT (por exemplo: encefalopatia de Wernicke, acidose lática, insuficiência cardíaca congestiva), o paciente deverá receber 200-300mg de tiamina IV 3 vezes ao dia até reversão dos sintomas, devendo, em seguida, receber manutenção de $50 \mathrm{mg} /$ dia IV por tempo indeterminado;

- o paciente deverá receber também complexo multivitamínico com demais micronutrientes (exemplo: Frutovitan $^{\circledR}$ );

- a via parenteral deverá ser substituída pela via oral para a suplementação de tiamina tão logo a condição clínica do paciente possibilite a transição. 


\section{Limitações identificadas}

Ressaltamos que uma das limitações para este protocolo foi a carência de estudos multicêntricos e randomizados capazes de estabelecer doses individualizadas para cada população e manifestação clínica. Portanto, nos baseamos nas diretrizes atualmente utilizadas em grandes centros de saúde e estudos observacionais que comprovam a relação entre a deficiência de tiamina e suas complicações mais graves. , $, 7,10,12-14^{-1}$

Apesar dessas limitações, a implantação desse protocolo é válida pois permite: (1) reconhecer fatores de risco para deficiência de tiamina ainda em fase precoce, de preferência na ocasião da admissão hospitalar, favorecendo a prevenção

\section{REFERÊNCIAS}

1. Correia, MI, Waitzberg, DL. The impact of malnutrition on morbidity, mortality, length of hospital stay and costs evaluated through a multivariate model analysis. Clin Nutr. 2003;22(3):235-9.

2. Toledo D, Castro M. Terapia nutricional em UTI. Rio de Janeiro: Rubio; 2015.

3. Frank LL. Thiamin in Clinical Practice. JPEN J Parenter Enteral Nutr. 2015;39(5):503-20.

4. Roman-Campos D, Cruz JS. Current aspects of thiamine deficiency on heart function. Life Sci. 2014;98(1):1-5.

5. Gropper SS, Smith JL, Groff JL. Advanced nutrition and human metabolism. 5. ed. Belmont (CA): Wadsworth; 2009.

6. Frank RA, Leeper FJ, Luisi BF. Structure, mechanism and catalytic duality of thiamine-dependent enzymes. Cell Mol Life Sci. 2007;64(7-8):892-905.

7. Dounousi E, Zikou X, Koulouras V, Katopodis K. Metabolic acidosis during parenteral nutrition: pathophysiological mechanisms. Indian J Crit Care Med. 2015;19(5):270-4.

8. Donnino MW, Carney E, Cocchi MN, Barbash I, Chase M, Joyce $\mathrm{N}$, et al. Thiamine deficiency in critically patients with sepsis. J Crit Care. 2010;25(4):576-81. de complicações graves; (2) identificar manifestações clínicas, ainda que sutis, associadas a deficiência dessa vitamina; e (3) orientar de forma didática e sistematizada a reposição em pacientes de risco que necessitarem de NPT.

\section{CONCLUSÃO}

A deficiência de tiamina traz complicações severas para pacientes em terapia nutricional parenteral, com piores desfechos e aumento da morbidade. Sabendo que tais complicações são preveníveis através da suplementação de vitamina $\mathrm{B} 1$ nestes pacientes sob risco, o protocolo proposto é necessário.

9. Singer P, Berger MM, Van Der Berghe G, Biolo G, Calder P, Forbes A, et al. ESPEN guidelines on parenteral nutrition: intensive care. Clin Nutr. 2009;28(4):387-400.

10. American Society for Parenteral and Enteral Nutrition (ASPEN) Board of Directors. Clinical guidelines for the use of parenteral and enteral nutrition in adult and pediatric patients. JPEN J Parenter Enteral Nutr. 2009;33(3):255-9.

11. Ferrie S. Case report of acute thiamine deficiency occurring as a complication of vitamin-free parenteral nutrition. Nutr Clin Pract. 2012;27(1):65-8.

12. Manzanares W, Hardy G. Thiamine supplementation in the critically ill. Curr Opin Clin Nutr Metab Care. 2011;14(6):610-7.

13. Giacalone M, Martinelli R, Abramo A, Rubino A, Pavoni V, Iacconi $\mathrm{P}$, et al. Rapid reversal of severe lactic acidosis after thiamine administration in critically ill adults: a report of 3 cases. Nutr Clin Pract 2015;30(1):104-10.

14. Sequeira Lopes da Silva JT, Almaraz Velarde R, Olgado Ferrero F, Robles Marcos M, Pérez Civantos D, Ramírez Moreno JM, et al. Wernicke's encephalopathy induced by total parenteral nutrition. Nutr Hosp. 2010;25(6):1034-6.

\section{Como citar:}

Medeiros LR, Beltrão BA, Mourão AC, Aragão NL, Furtado AH Júnior, Peixoto AA Júnior. Protocolo de uso suplementar de tiamina em pacientes utilizando nutrição parenteral total no Hospital Universitário Walter Cantídio (HUWC). Rev Med UFC. 2018 jan-mar;58(1):80-83. 